\title{
Experimentally induced helper dispersal in colonially breeding cooperative cichlids
}

\author{
D. Heg • Z. Heg-Bachar • L. Brouwer • \\ M. Taborsky
}

Received: 29 September 2006 / Accepted: 8 November 2007 /Published online: 1 January 2008

(C) Springer Science + Business Media B.V. 2007

\begin{abstract}
The 'benefits of philopatry' hypothesis states that helpers in cooperatively breeding species derive higher benefits from remaining home, instead of dispersing and attempting to breed independently. We tested experimentally whether dispersal options influence dispersal propensity in the cooperatively breeding Lake Tanganyika cichlids Neolamprologus pulcher and $N$. savoryi. Cooperative groups of these fishes breed in densely packed colonies, surrounded by unoccupied, but apparently suitable breeding habitat. Breeding inside colonies and living in groups seems to benefit individuals, for example by early detection and deterrence of predators. We show that despite a slight preference of both species for habitat with a higher stone cover, $40 \%$ of the preferred habitat remained unoccupied. On average, the colonies contained a higher number of (1) predators of adults, juveniles and eggs, (2) shelter competitors, and (3) other species including potential food competitors, compared to the outside colony habitat. Apparently,
\end{abstract}

D. Heg $(\bowtie) \cdot$ Z. Heg-Bachar $\cdot$ M. Taborsky

Department of Behavioural Ecology, Zoological Institute, University of Bern,

CH-3032 Hinterkappelen, Switzerland

e-mail: dik.heg@esh.unibe.ch

L. Brouwer

Animal Ecology Group,

Centre for Ecological and Evolutionary Studies,

University of Groningen,

9750AA Haren, The Netherlands habitat differences cannot explain why these cichlids breed in colonies. Accordingly, dispersal may not be limited by a lack of suitable breeding shelters, but by the relatively higher risk of establishing an outsidecompared to a within-colony breeding territory. To test whether cichlids prefer within- to outside-colony breeding territories, we provided breeding shelters inside the colony and at the colony edge and studied helper dispersal. As expected, significantly more shelters were occupied within the colony compared to the edge. New breeding pairs with several helpers occupied these shelters. We conclude that although breeding habitat is plentiful outside the colonies, helpers delay dispersal to obtain a higher quality breeding position within the group or colony eventually, or they disperse in groups. Our results suggest that (1) group augmentation and Allee effects are generally important for dispersal decisions in cooperatively breeding cichlids, consistent with the 'benefits of philopatry hypothesis', and (2) habitat saturation cannot fully explain delayed dispersal in these species.

Keywords Dispersal - Cooperative breeding · Habitat saturation · Allee effects · Cichlidae

\section{Introduction}

Delayed subordinate dispersal is a key feature of all cooperatively breeding animals (Stacey and Koenig 1990; Koenig et al. 1992; Emlen 1995; Choe and 
Crespi 1997; Hatchwell and Komdeur 2000; Koenig and Dickinson 2004). Breeder removal experiments have shown that subordinates might delay dispersal, (1) to queue for the breeding position in the group (e.g. Balshine-Earn et al. 1998; Field et al. 1999; Goldizen et al. 2002; Buston 2003; Dierkes et al. 2005; Stiver et al. 2006); (2) to wait for a breeding vacancy in a nearby territory (e.g. Pruett-Jones and Lewis 1990; Komdeur 1994); or (3) to establish a territory by 'budding-off' a part of the natal territory (e.g. Stacey and Koenig 1990; Komdeur and Edelaar 2001). Finally, correlative and experimental data show that helpers strategically stay and queue or disperse and breed on their own in dependence of the relative quality of the alternative breeding sites available or provided (Stacey and Ligon 1987, 1991; Ligon et al. 1991; Komdeur 1992; Heg et al. 2004; Bergmüller et al. 2005a,b). Subordinates may not accept independent breeding options and rather stay in the group (Taborsky 1984; Ligon et al. 1991; Duplessis 1992; Macedo and Bianchi 1997), which suggests that 'the benefits of philopatry' (Stacey and Ligon 1991) may outweigh the benefits of independent breeding. For instance, Macedo and Bianchi (1997) found no differences in the quality of the habitat comparing areas occupied by guira cuckoo Guira guira cooperative breeding territories and adjacent areas not occupied by these cuckoos, and concluded that habitat saturation is unlikely to explain delayed dispersal and delayed independent breeding in this species.

The ecological constraints and benefits of philopatry hypotheses (which are essentially 'two sides of the same coin') both seem to operate in our study species, the cichlids Neolamprologus pulcher and N. savoryi (Taborsky 1984, 1994; Heg et al. 2004, 2005a). These small fish are endemic to Lake Tanganyika, locally very abundant, and co-occur in water depths of 2-25 m in various habitats all along the shores of the lake (Konings 1998). Within the Lamprologini, at least 19 species show cooperative breeding (Taborsky 1994; Heg and Bachar 2006). Breeders lay and tend their eggs in a shelter under rocks or in crevices, and where sand and debris covers the rocks, breeders and helpers remove it to create a breeding shelter and hiding shelters for all group members (where fish retreat from predator attacks, Balshine et al. 2001; Werner et al. 2003). The large group members defend the territory against piscivorous Lamprologine cichlids
(Lepidiolamprologus spp., Altolamprologus spp., Lamprologus spp.) and mastacembelid eels preying on helpers and fry (Taborsky and Limberger 1981; Taborsky 1984; Balshine et al. 2001; Heg et al. 2005a). This is probably not without risks, since many group members have scars from predator attacks (Balshine et al. 2001). As soon as a predator enters the colony, the fish outside shelters, e.g. when feeding in the water column, flee into their shelters, which is a remarkably synchronous reaction of members of different groups. This strongly suggests that fish from within-colony groups copy the fleeing behaviour of fish from colony edge groups, and thereby reduce their predation risk.

We have experimentally shown that $N$. pulcher helpers stay closer to their home territory, delay dispersal and independent breeding under the risk of predation (Heg et al. 2004). Furthermore, N. pulcher helpers preferably visit neighbouring groups within a $3 \mathrm{~m}$ radius around their home territory, which are also used as refuge ('extended safe havens') when the risk of predation at home is experimentally increased with decoys (Bergmüller et al. 2005a). Helpers visited other groups more often when it was unlikely that they would obtain a breeding position by queuing at home, suggesting visiting behaviour is a prospecting strategy for future breeding possibilities. Apparent prospecting behaviour has also been described for $N$. savoryi (Kondo 1986).

In our study area, the habitat appears to be very homogeneous and suitable for breeding throughout: a flat sand layer with half-submerged rocks. Yet, reproductively mature helpers (see Heg et al. 2006) delay dispersal and queue for a breeding position in their own (Balshine-Earn et al. 1998; Dierkes et al. 2005; Stiver et al. 2006) or a nearby group (Stiver et al. 2004), despite of ample free space. $N$. savoryi is very similar in general appearance, ecology and behaviour to $N$. pulcher, and both are often found in mixed colonies (Fig. 1, see also Heg et al. 2005a), interspersed with unoccupied, but apparently suitable habitat. These colonies are located on the exact same spot year-after-year, and from observations extending over a period of 8 years we have no evidence to suggest they are systematically expanding (which would suggest these cichlids had recently colonised a new habitat). The availability of suitable, yet unoccupied habitat is not a unique feature of cooperatively breeding cichlids (see review by Stamps 2001). For example, Booth (1992) showed 


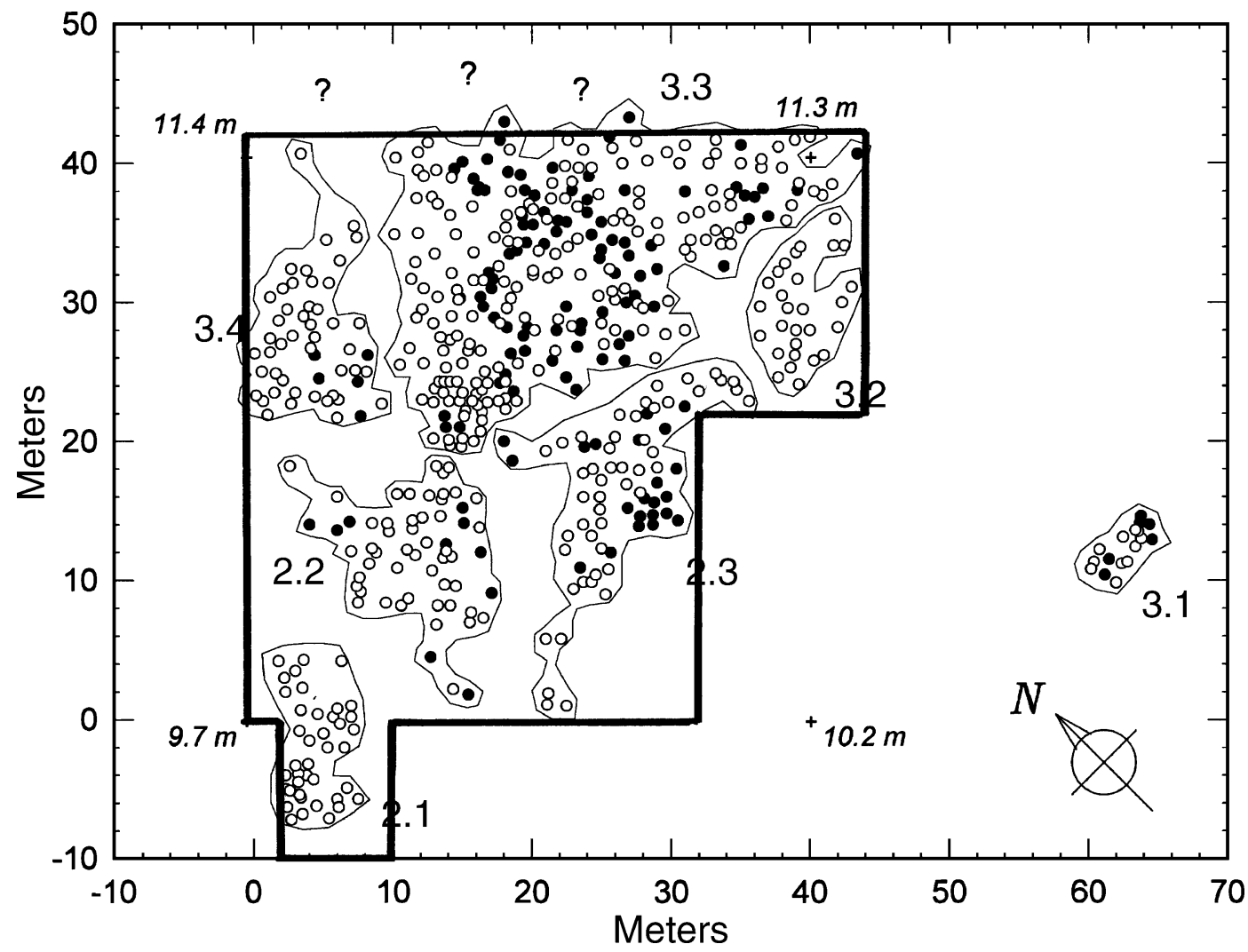

Fig. 1 Distribution of the cooperatively breeding cichlids $N$. pulcher (open circles) and $N$. savoryi (closed circles) in our study area (bold line) in January-April 2003; colonies 2 with three sub-colonies (2.1, 2.2 and 2.3) and 3 with four subcolonies (3.1 to 3.4). Each dot represents a patch of stones defended by cichlids. Some breeding groups defend two to three, rarely up to five such patches. Colony 3.3 extends further

experimentally that domino damselfish Dascyllus albisella preferred to settle with conspecific juveniles.

In the first part of this paper we quantify and compare the within-colony and outside-colony habitat and species composition, i.e. the density of potential shelter competitors and predators. We use these data to test whether colony breeding might be due to habitat selection and preferences. Both study species are substrate breeders, so the availability of shelters is an important determinant of colonisation potential. Food availability is less likely to vary locally, since these cichlids are mainly zooplanktivores (Kondo 1986; Gashagaza 1988), and plankton densities show rather large-scale and high temporal variability (S. Balshine and M. Taborsky, personal observations; see also Kurki et al. 1999). Additional food is taken from the stones (Kondo 1986, personal observations), so food availability might show some relationship with to the north and north-east, as indicated by the questions marks. Note the vast stretches of unoccupied habitat (not shown: unoccupied but similar habitat extending to the right from the graph $>50 \mathrm{~m}$ towards colonies 1 and 8 , to the left from the graph $>100 \mathrm{~m}$, and downwards from the graph $>100 \mathrm{~m}$ towards colony 7). Also depicted is the depth at four corner points (marked with crosses)

stone cover. We measured the densities of shelter competitors and predators in transects.

In the second part of the paper we tested experimentally (1) whether breeding sites provided to helpers would cause them to disperse, (2) whether within colony breeding sites are more readily accepted than outside colony sites; a higher acceptance rate of within colony sites will ultimately create clusters of groups into colonies. We assess (3) whether any difference in acceptance rates is due to (a) active avoidance of outside-colony shelters or (b) preferred visiting of nearby groups (see Bergmüller et al. 2005a) and/or (c) avoidance of shelters visited by other fish (i.e. predators or shelter competitors). Further, we assess (4) if helpers disperse in groups and tested whether (5) dispersal behaviour depends on helper size and on the vicinity of available vacancies. For reasons given above, we expected more dispersal events to occur 
within colony areas than at colony edges, dispersal to occur in groups, large rather than small helpers to disperse, and dispersal to occur preferably to nearby shelters.

\section{Materials and methods}

Study site and subjects

The study site was located at the southern tip of Lake Tanganyika at Kasakalawe Point near Mpulungu, Zambia $\left(8^{\circ} 46.849^{\prime} \mathrm{S}, 31^{\circ} 04.882^{\prime} \mathrm{E}\right)$. Cichlids were studied by SCUBA diving from 5 March-27 May 2002 and 2 February-21 April 2003. The study site is a sandy area with half submerged rocks at 9.0-11.5 m depth. The experiments were conducted at colonies 2 and 3 (Fig. 1, colony boundaries were operationally defined). In these colonies, N. pulcher and N. savoryi groups breed at very high densities in distinct territories consisting of patches of stones. All focal territories and dispersal shelters were marked with numbered rocks and mapped using a $2 \times 2 \mathrm{~m}$ grid made with ropes. This allowed us to determine the nearest neighbour distances, the distance between each experimental dispersal shelter and its nearest same species group $(0.1 \mathrm{~m}$ resolution) and the number of same species groups within a radius of $1 \mathrm{~m}$ from the territory edge. However, since the latter two factors were highly correlated and could be used interchangeably in all analyses, only the data on nearest (experimental) neighbour distances are presented here. The mean nearest neighbour distance in colonies 2 and 3 was $0.910 \mathrm{~m}$, compared to an expected mean nearest neighbour distance of $1.256 \mathrm{~m}$, based on the average density (Fig. 1). Hence, experimental dispersal shelters outside the colony (see below) were created $1 \mathrm{~m}$ from the colony edge.

\section{Habitat measurements}

Habitat measurements were carried out in 2003 by Z. H.-B. and D.H. The study area was divided into a grid of $4212 \times 2 \mathrm{~m}$ squares, encompassing both colonies, except the area to the right surrounding colony 3.1 (Fig. 1). For each square we determined: (1) the depth measured with a Cressi Archimedes diving computer ( $0.1 \mathrm{~m}$ accuracy, the computer adjusts the measurements for above-water air-pressure); (2) the percent- age of visible stone cover (estimated in 10\% classes). Depth cannot be a general cause for these cichlids to reject certain habitats, since both species occur from depths of 6.5-7 m downwards in our Kasakalawe study area, and from $2 \mathrm{~m}$ depth downwards in other areas. However, to correct for potential confounding effects of depth within our study area (Fig. 1), this variable was included in the analyses.

Species composition

The species composition comparing within- and outside-colony habitats was determined in 2002 by D.H. Sixteen $20 \times 1 \mathrm{~m}$ fish counting transects were laid in colonies 2 and 3, each transect divided in a part covering the colony and a part covering the adjacent area not inhabited by $N$. pulcher or $N$. savoryi. All cichlids and non-cichlids occurring were counted per species and standard length (SL) estimate in $1 \mathrm{~cm}$ classes, separated for the within- and outside-colony parts of each transect, and converted to number of fish per $10 \mathrm{~m}^{2}$. Catfish (mainly Synodontis spp.) were not counted, because they are nocturnal and hide under rocks during daytime. The percentage of visible stone cover (estimated in 10\% classes) per transect was estimated for within- and outside-colony parts as well. Species were determined using standard identification guides (Brichard 1997, 1999; Konings 1998).

\section{Dispersal experiment}

Dispersal shelters at the edge of the colonies ('outsidecolony shelters') were created as follows $(n=15)$. Two groups at the edge of a colony were selected haphazardly and group composition was determined (numbers and sizes of breeding males, females, helpers and free swimming fry). At $1 \mathrm{~m}$ distance from both groups an artificial high quality breeding site was created, by removing sand between and underneath the rocks and adding small rocks and empty snail shells (snail shells are often used by smaller helpers to hide in). Using a similar procedure, Balshine et al. (2001) artificially enlarged territories which tended to attract additional group members, so we are confident that these experimentally created dispersal shelters provided suitable high quality breeding habitat for both species. To determine which helpers visited these shelters, we captured two to four helpers in each of the two adjacent groups, measured 
body size (standard length SL from tip of the snout to the tail base to the nearest $0.5 \mathrm{~mm}$ ), marked them individually by injecting non-toxic acrylic paint into scale pouches and by taking fin clips of the dorsal and anal fins, and released them. Other group members were recognisable from estimates of their SL relative to the marked helpers and from natural body markings. SL of unmarked individuals was estimated by placing a millimetre board in the territory $(0.5 \mathrm{~mm}$ classes), and was calibrated to true SL by similarly estimating the size of the marked individuals. Marking and measuring of all group members was not attempted to avoid groups dissolving due to the disturbance (D. Heg and M. Taborsky, personal observation). Once per week during 6 weeks, all visitors and permanent occupants of the dispersal shelters were determined in a 5 min observation (species, SL estimated with measuring board). All fish larger than $15 \mathrm{~mm} \mathrm{SL}$ were counted. One shelter was only checked for 4 weeks, but already had a permanent occupant. Occupants were defined as individuals aggressively defending all or part of the site against all other shelter competitors, and are henceforth called 'dispersers'. 'Visitors' were defined as fish entering the shelter area, but not aggressively defending it. Visitors typically stayed less than a minute in the shelter, and afterwards swam back to their home territory.

Dispersal shelters within the mixed colonies were created by temporarily removing complete $N$. savoryi groups ( $n=20$, 'within-colony shelters'), selected haphazardly. This approach was necessary since the densities were so high within colonies that it was often impossible to find suitable, unoccupied patches of stones to create artificial dispersal vacancies. All stones of the manipulated territories were removed, and the shelters were reconstructed to resemble the types of vacancies created on the colony edges. The complete $N$. savoryi breeding groups were removed by putting tent-nets over the whole territory and anaesthetising the group members with Eugenol before catching them with hand nets. All breeders and helpers recovered from this procedure within 5 min and were kept just outside the colony in large pouch-nets, and they were fed TetraMin cichlid food daily until release after the experiment. No attempt was made to mark any of the large number of group members adjacent to these removal groups due to time constraints. During the first 10 days and subsequently once a week for up to 4 weeks all visitors and dispersers at each shelter were determined in a $5 \mathrm{~min}$ observation (species, SL estimated as outlined above, defence behaviour as criterion). Again, all fish larger than $15 \mathrm{~mm}$ SL were counted. Most shelters were already permanently occupied within 7 days, in which case the removed group members were released back into their territory to minimize their time in captivity.

As the distance the experimental shelters and the nearest breeding groups in the outside colony treatment was fixed to $1 \mathrm{~m}$, we attempted to create similar nearest $N$. pulcher neighbour distances in the within colony treatment. Due to the high densities and variability in group spacing within colonies this was not entirely possible. However, the average distance between the dispersal shelter and its nearest $N$. pulcher neighbour in the within-colony treatment was $0.80 \mathrm{~m}$ (range $0-4 \mathrm{~m}$ ), which was not significantly different from the fixed $1 \mathrm{~m}$ distance used in the outside treatment (Binomial Test, $P=0.12$ ) and the average number of $N$. pulcher group territories within $1 \mathrm{~m}$ was 2.5 compared to 2 in the outside treatment $(P=0.12)$. The outside-colony dispersal shelters were created near two $N$. pulcher groups, the dominant species, since $N$. savoryi tends to breed more within the colonies (see Fig. 1). Nevertheless, all dispersal shelters, including the outside colony shelters, had one to five neighbouring $N$. savoryi groups within 0.1 to $3.8 \mathrm{~m}$. Furthermore, the results on dispersal behaviour and the number of visitors were corrected for the number of neighbouring groups.

\section{Observations of visitors}

The average number of visits by each fish species were entered into the analyses to test whether visits by other species might have influenced the visits and acceptance rate of shelters by the two focal cooperatively breeding cichlids. In total, 175 and 96 observations of 5 min were conducted to count visitors to within- and outside-colony dispersal shelters, respectively.

\section{Data analyses}

The relationship between the number of $N$. pulcher and $N$. savoryi groups in the $2 \times 2 \mathrm{~m}$ squares depending on the stone cover, depth and the number of groups in the neighbourhood were analysed with Poisson regressions in R1.0.8 (GLM with Poisson errors, Crawley 2002, 
pp. 537-562, pp. 718-720). Interactions were also tested, but were all non-significant. In case of overdispersion the significance levels were computed with the $F$-test (Crawley 2002, p.541). All other analyses were performed with SPSS 11.0.

To compare the number of individuals per fish species per $10 \mathrm{~m}^{2}$ inside the colony vs outside the colony, counts of fish per transect per in- or outside part were computed separately and square root (number+3/8) transformed (Zar 1984) to obtain a normal distribution. To simplify the analyses, we lumped the following data of rare visitors into new categories of types of species: (1) Predators of cichlid fry: Altolamprologus calvus, small mastacembelid eels (mainly Aethiomastacembelus spp.), Gnathochromis pfefferi, Lamprologus callipterus and Lobochilotes labiatus; (2) Predators of fry, helpers and breeders: large mastacembelid eels (mainly Caecomastacembelus frenatus), Lepidiolamprologus attenuatus, L. elongatus, Lamprologus lemairii, Neolamprologus sexfasciatus; (3) Other fish: Cyathopharynx furcifer, Limnotilapia dardennii, Neolamprologus caudopunctatus, Tropheus moorii, Xenotilapia flavipinnis, X. sima and $X$. spilopterus. This lumping gave a total number of nine 'species types': J. ornatus, N. modestus, $N$. tetracanthus, T. temporalis (all four potential shelter competitors), P. microlepis (scales eater), T. vittatus (egg predator), Predators of fry, Predators of all, and Others. We then used a paired design GLM with normal errors on the transformed fish counts, i.e. comparing counts of the inside vs outside part of each transect (within-subject effect 'colony', Crawley 2002), with the effects species type (nine types) and their interaction.
Estimates of visiting rate per 5 min until the shelter was finally occupied were averaged per shelter for the analyses. The average number of visits per shelter by $N$. pulcher and $N$. savoryi, respectively, were square root (visits $+3 / 8$ ) transformed (Zar 1984) before analyses with the General Linear Models (GLM). The transformed visit rates of these two species followed a normal distribution. To test whether some dispersal shelters were more often visited due to cooperatively breeding cichlids preferably visiting nearby groups, or whether these cichlids actively avoided outside-colony shelters compared to withincolony shelters, we analysed visiting behaviour in relation to the number of neighbouring groups within a $3 \mathrm{~m}$ radius around the dispersal shelters (covariate) and treatment (fixed effect, within-colony or outside colony shelter) using a Multivariate GLM (two dependent variables: number of visits by $N$. pulcher and $N$. savoryi), this test includes two univariate tests (testing for 'between-subjects effects').

\section{Results}

Colonial breeding and habitat measurements

Colonial breeding in both species appeared not simply due to habitat preferences (Table 1). Even when corrected for the effects of 'habitat' (stone cover, depth) and the competitive effect of the number of groups of the other species in the same square, there was a strong and significant spatial autocorrelation between the number of groups in neighbouring

Table 1 Results of two Poisson regressions relating the number of groups per $2 \times 2 \mathrm{~m}$ square of $N$. pulcher or $N$. savoryi to depth, stone coverage, the number of groups of the other species, and the number of groups in neighbouring squares $(n=421)$

\begin{tabular}{|c|c|c|c|c|c|c|}
\hline \multirow{2}{*}{$\frac{\text { Dependent variable: }}{\text { Independent variables }}$} & \multicolumn{3}{|c|}{ Number of $N$. pulcher $^{\mathrm{a}}$} & \multicolumn{3}{|c|}{ Number of $N$. savoryi ${ }^{\mathrm{b}}$} \\
\hline & Coefficient \pm SE & $z$ & $P$ & Coefficient \pm SE & $z$ & $P$ \\
\hline Constant & $-5.78 \pm 1.21$ & -4.8 & $<0.001$ & $-16.45 \pm 2.57$ & -6.4 & $<0.001$ \\
\hline Depth & $0.47 \pm 0.11$ & 4.3 & $<0.001$ & $1.41 \pm 0.23$ & 6.0 & $<0.001$ \\
\hline Stone cover & $0.70 \pm 0.19$ & 3.6 & $<0.001$ & $0.05 \pm 0.33$ & 0.1 & 0.89 \\
\hline Groups N. pulcher & - & - & - & $-0.20 \pm 0.09$ & -2.1 & 0.034 \\
\hline Groups $N$. savoryi & $-0.17 \pm 0.08$ & -2.1 & 0.035 & - & - & - \\
\hline Neighbours & $0.25 \pm 0.03$ & 7.3 & $<0.001$ & $0.26 \pm 0.07$ & 3.6 & $<0.001$ \\
\hline
\end{tabular}

Depicted are the coefficients \pm SE together with the test statistic $z$ and $P$ values

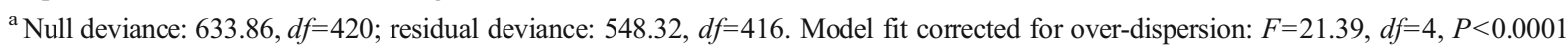

${ }^{\mathrm{b}}$ Null deviance: $422.68, d f=420$; residual deviance: $363.89, d f=416$ 
squares ('neighbours', see Table 1). Apparently, habitat characteristics per se cannot account fully for the fact that both species occur in distinct colonies and about $40 \%$ of the preferred stony habitat remains actually unoccupied (Fig. 2). Alternatively, the study species might be forced to breed in colonies due to higher densities of shelter competitors and predators in the surrounding areas, which is investigated below.

\section{Species composition}

The species composition of the within- and outsidecolony habitat was compared using the fish counts in the transects. Consistent with the above results, the within-colony part of the transects had a significantly higher stone cover $($ mean $\% \pm \mathrm{SE}=49.1 \pm 4.2$, median $=$ 47.5, range $=25-75$ ) compared to the outside part $($ mean $\% \pm \mathrm{SE}=40.9 \pm 4.3$, median $=37.5$, range $=15-$ 70; Wilcoxon's test: $z=-2.79, n=16, P=0.005$ ).

Cooperatively breeding cichlids did not avoid habitat occupied by predators or shelter competitors (Fig. 3). On the contrary, virtually all fish species tended to be more abundant within the colonies, compared to the adjacent part outside the colonies of $N$. pulcher and N. savoryi (Fig. 3a). This result was shown by the paired-data GLM on the square root

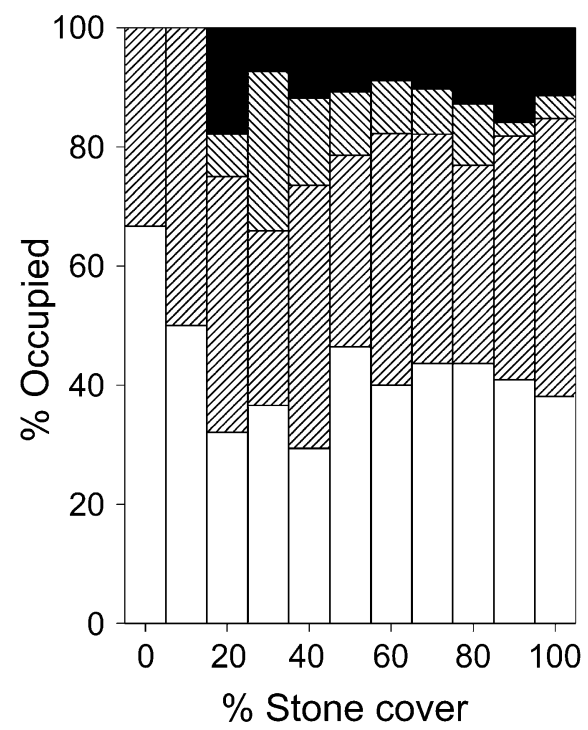

Fig. 2 The extent of unoccupied habitat from an analysis of $4212 \times 2 \mathrm{~m}$ squares scored for percentage of visible stone coverage ( $10 \%$ classes), encompassing both colonies (except 3.1). White unoccupied, right hatched only N. pulcher, left hatched only $N$. savoryi, black both species occurring. $N$. savoryi avoids habitat with almost no visible stone cover $(<20 \%)$ (fish count $+3 / 8)$ transformed data ( $n=144$ pairwise counts per species type, see Statistics for categories): the within-subject effect 'colony' (within- or outside the colony) approached significance $\left(F_{1,135}=2.8, P=\right.$ 0.099), depending on the species type (species type $\times$ colony: $F_{8,135}=1.5, P=0.15$; with between-subject effect, species type: $\left.F_{8,135}=11.5, \mathrm{P}<0.0001\right)$. Cichlids that were significantly more abundant within the colonies included the large fish predator $L$. elongatus (Wilcoxon's Test, $z=-2.02, n=16, \mathrm{P}<0.05$ ) and the egg predator T. vittatus (Wilcoxon's Test, $z=-2.59$, $n=16, P=0.01$ ). The only species significantly more abundant outside the colony was the shelter competitor N. modestus (Wilcoxon's Test, $z=2.59, n=16$, $P=0.01)$.

Fish species within the colonies were also similar in sizes to the same species outside the colonies (Fig. 3b, $n=1,810$ individuals of 20 species, excluding four species seen only within or only outside the colony, GLM on SL: effect of species: $F_{19,1770}=$ 1,78.0, $P<0.001$; colony: $F_{1,1770}=0.1, P=0.74$; interaction: $\left.\mathrm{F}_{19,1770}=3.0, P<0.001\right)$. The significant interaction was due to large mastacembelid eels being larger outside the colony than within the colony $(t=$ $-2.2, P=0.028)$ and otherwise due to some species being non-significantly larger within or outside the colonies (Fig. 3b, in total seven species tended to be larger and 12 species tended to be smaller within the colonies, one tie, compared to outside the colonies). The major predators occurring in high densities in the area tended to be larger within the colony than outside (L. elongatus: 78.9 vs $74.8 \mathrm{~mm} \mathrm{SL}, n=36$ and 25 respectively; L. lemairii: 90.0 vs $80.0 \mathrm{~mm} \mathrm{SL}, n=15$ and 9 respectively) or similar in size (L. attenuatus: 60.0 vs $60.0 \mathrm{~mm} \mathrm{SL}, n=24$ and 12 respectively). In contrast, the only egg predator, T. vittatus, although occurring in significantly higher densities within the colony (Fig. 3a), tended to be smaller within the colonies (Fig. 3b, 32.9 vs $35.2 \mathrm{~mm} \mathrm{SL}, n=185$ and 103 respectively).

Visits to the experimental shelters

In total 985 within- and 201 outside-colony shelter visitors were recorded in the $5 \mathrm{~min}$ observations, of 20 species of fish in total. All shelters were regularly visited by members of several cichlid species. The most common visitors were (frequency within/outside colony): N. savoryi (332/13), N. pulcher (296/48), T. 


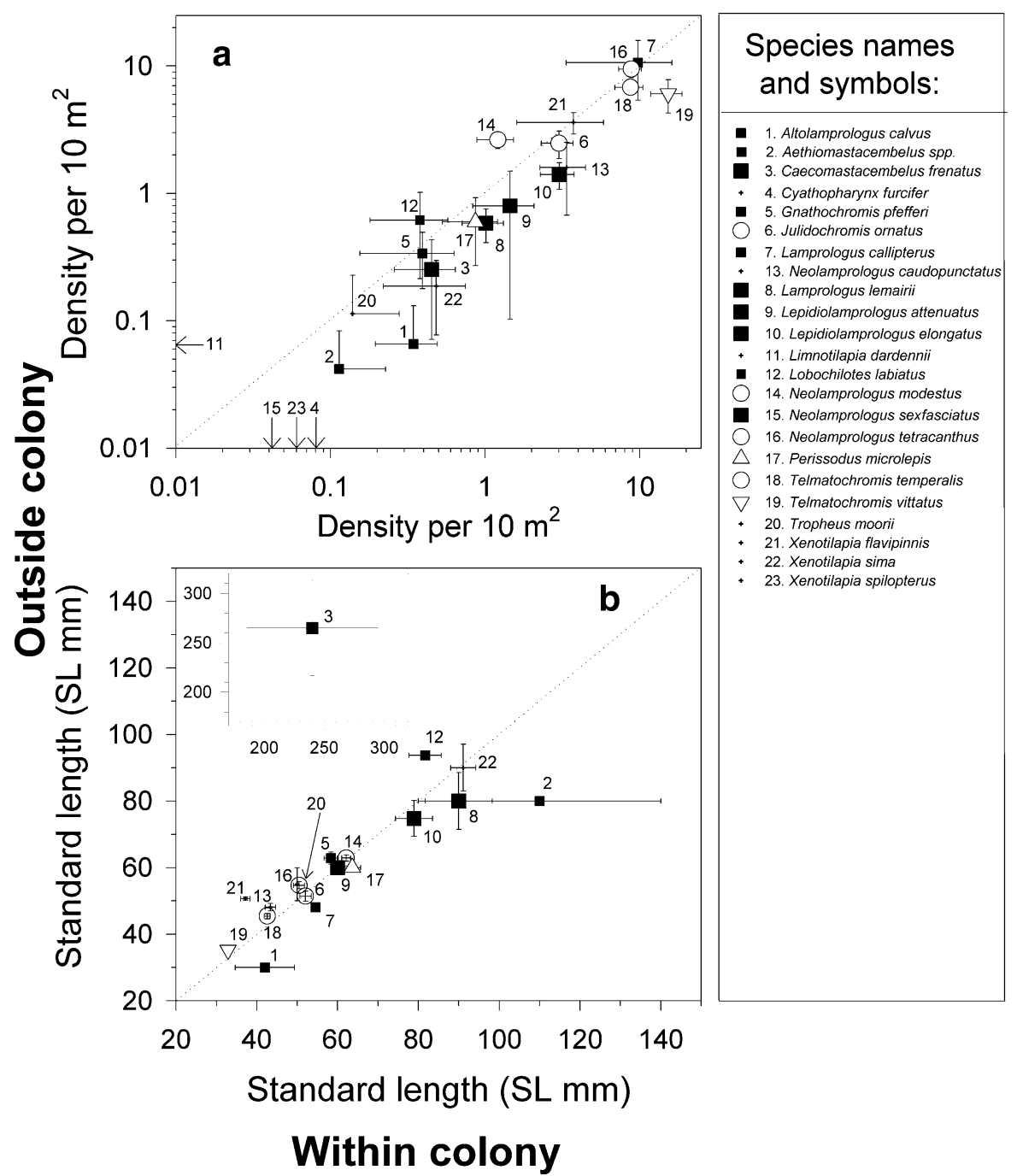

Fig. 3 Arithmetic means with SE of (a) densities and (b) estimated standard lengths of fish species occurring within the colonies of $N$. pulcher and $N$. savoryi, compared to the same measures outside the colonies ( $n=16$ pairwise measures). Arrows in a denote the four species not detected either within or outside the colonies, which are therefore missing from graph b. Inset shows body lengths of the large mastacembelid eels (mainly Caecomastacembelus frenatus) belonging to b. Dotted

temporalis (66/35), J. ornatus (79/12), N. tetracanthus (47/16), and N. modestus (36/17). Overall, visitation rates of $N$. pulcher and $N$. savoryi were not correlated (Spearman $r_{\mathrm{s}}=0.19, n=35, P=0.28$ ).

To test whether visits by shelter competitors, fish predators, egg predators or fish-scale eaters on average made some dispersal shelters less attractive for visits by $N$. pulcher and $N$. savoryi, two multiple regression analyses were performed on the squareroot transformed visits by $N$. pulcher or $N$. savoryi, lines in both graphs show the null expectation, i.e. when densities and standard lengths would not differ between the within- and outside-colony parts of the transects. White circles potential shelter competitors; white triangle pointed upwards scales eater; white triangle pointed downwards egg predator; small black squares predators of fry; large black squares predators of fry, juveniles and adults; crosses other cichlid species

with forward selection of the visitation rates per species. The visitation rate by $N$. pulcher was positively related to the visitation rate by $J$. ornatus $(t=2.3, P=0.026$, coefficient \pm SE: $0.72 \pm 0.31)$ and the visitation rate by $N$. savoryi was positively related to the visitation rate by $J$. ornatus $(t=2.9, P=0.007$, coefficient \pm SE: $0.72 \pm 0.25), N$. caudopunctatus $(t=$ 3.2, $P=0.004$, coefficient \pm SE: $7.73 \pm 2.45)$ and $X$. sima ( $t=2.6, P=0.015$, coefficient \pm SE: $1.97 \pm 0.76)$. Hence, visits by the 19 other species did not 
negatively influence the visitation rates by both cooperatively breeding cichlids; if any, there were positive effects, e.g. due to similar preferences for certain shelters. $N$. savoryi visited within-colony shelters significantly more often than outside-colony shelters (Mann-Whitney $U$ test, $U_{20,15}=29, P<$ 0.001). A similar, but non-significant tendency was apparent in $N$. pulcher $\left(U_{20,15}=105.5, P=0.14\right)$ and $N$. tetracanthus $\left(U_{20,15}=106.5, P=0.15\right)$, but not so in $N$. modestus $\left(U_{20,15}=125, P=0.42\right)$. Other Lamprologine species ((Neo)lamprologus spp., Lepidiolamprologus spp., Altolamprologus spp. and J. ornatus) were also significantly more abundant at vacant shelters within the colony $\left(U_{20,15}=58.5, P=0.002\right.$, Fig. 4$)$, whereas all other species were more abundant at shelters

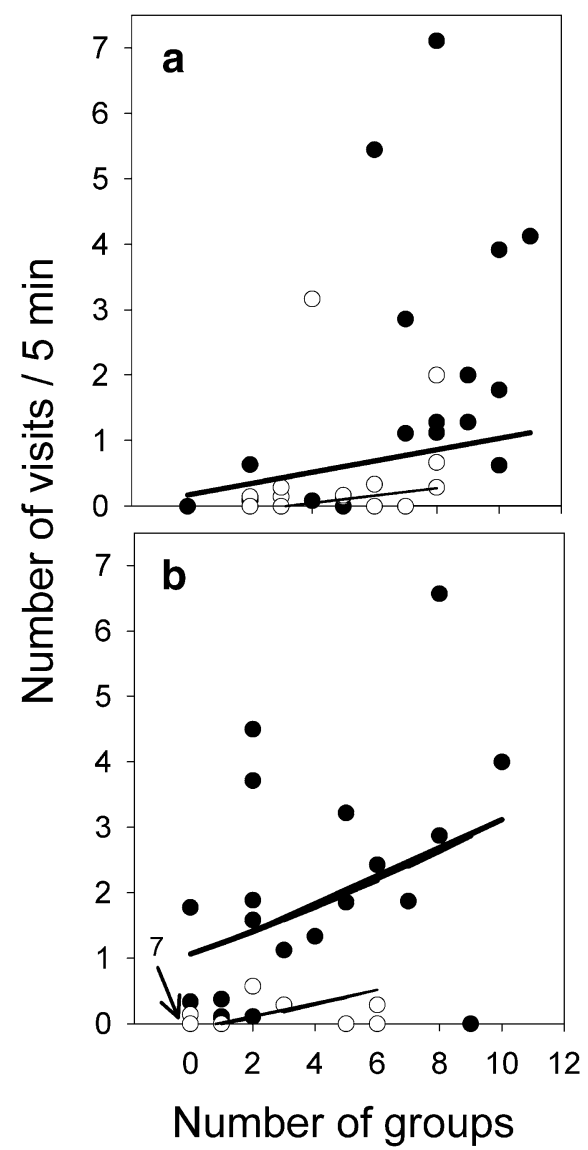

Fig. 4 Visitation rates of a $N$. pulcher and $\mathbf{b} N$. savoryi of the experimental dispersal shelters depending on the treatment (within-colony shelters, black circles and bold lines, $n=20$; or outside-colony shelters, white circles and thin lines, $n=15)$ and the number of neighbouring groups of a $N$. pulcher and $\mathbf{b} N$. savoryi within a $3 \mathrm{~m}$ radius around the shelters. Regression lines from the parameter estimates in Table 2 (back-transformed). For clarity, overlapping symbols are slightly off-set provided outside the colony $\left(U_{20,15}=90, P=0.046\right.$; including cichlids: Xenotilapia spp., Gnathochromis pfefferi, Lobochilotes labiatus, and non-cichlids: mastacembelid eels, catfish Synodontis spp.).

The visitation rates to within and outside colony shelters did not differ significantly between $N$. pulcher and $N$. savoryi (within and outside: Wilcoxon's Test $z_{20}=-0.56$ and $z_{15}=-1.69, P=0.57$ and 0.09 respectively). A multivariate GLM on the two dependent variables visitation rates by $N$. pulcher and $N$. savoryi, showed that within-colony shelters were visited more often than outside-colony shelters (Table 2). This was due to within-colony shelters having more neighbouring groups within a $3 \mathrm{~m}$ radius (and therefore, more potential visitors) and due to avoidance of outsidecolony shelters independent of the number of neighbours (Table 2). The latter result was only significant for $N$. savoryi $(P<0.001)$, but not for $N$. pulcher $(P=$ 0.12 , Fig. 4, Table 2).

The outside-colony dispersal shelters were predominantly visited by $N$. pulcher from the two nearest groups, compared to $N$. pulcher from other groups (77 vs $23 \%, n=48$, conservative binomial test on equal proportions: $P<0.001$ ). We used the group composition and visits from group members of these two nearest $N$. pulcher groups to test whether visitors really were prospecting dispersers, and not simply the largest fish in the group, i.e. the breeders. As expected, potential dispersers (i.e. the large, sexually mature helpers $>35 \mathrm{~mm} \mathrm{SL}, n=27$ visits $/ 106$ individuals available) were significantly more likely to visit the shelters than breeders $\left(n=5\right.$ of $60, G_{1}=5.7, P=$ $0.017)$, medium helpers (25.5-35 mm SL, $n=5$ of 57 , $\left.G_{1}=5.1, P=0.024\right)$ and small helpers $(15.5-25 \mathrm{~mm}$ SL, $n=0$ of $\left.13, G_{1}=5.6, P=0.018\right)$. All medium helpers visiting the shelters came from the two neighbouring territories $(100 \%, n=5)$, compared to $75 \%$ of the large helpers $\left(n=36, G_{1}=2.7, P=0.10\right)$.

Final occupants of the experimental shelters

Although both the experimental within- and outsidecolony dispersal shelters were visited, eventually cooperatively breeding cichlids were much more likely to permanently occupy and defend withincolony shelters $(85 \%$, counting shared shelters only once) than outside shelters (20\%, Table 3$)$. Competition for the within-colony shelters appeared higher compared to the outside-colony shelters: first, outside- 
Table 2 Results of a multivariate GLM on the average number of visits per experimental dispersal shelter by $N$. pulcher and $N$. savoryi (two dependent variables, both square-root (visits $+3 / 8$ ) transformed), depending on the number of neighbouring groups of both species within a $3 \mathrm{~m}$ radius around the shelter (covariates, both $d f=1$ ) and treatment (fixed effect, $d f=1$; within- or outside colony shelters, $n=20$ and 15 , respectively)

\begin{tabular}{|c|c|c|c|c|c|c|c|c|c|c|c|}
\hline \multirow[b]{3}{*}{ Independent variable } & \multirow{2}{*}{\multicolumn{3}{|c|}{ Multivariate tests }} & \multicolumn{8}{|c|}{ Univariate tests and coefficients $^{\mathrm{c}}$} \\
\hline & & & & \multicolumn{4}{|c|}{ Visits by $N$. pulcher } & \multicolumn{4}{|c|}{ Visits by $N$. savoryi } \\
\hline & $F^{\mathrm{a}}$ & $d f^{\mathrm{b}}$ & $P$ & $F$ & $d f^{\mathrm{b}}$ & $P$ & Coefficient \pm SE & $F$ & $d f^{\mathrm{b}}$ & $P$ & Coefficient \pm SE \\
\hline Constant & 26.9 & 2,30 & $<0.001$ & 8.16 & 1,31 & 0.008 & $0.399 \pm 0.189$ & 50.5 & 1,31 & $<0.001$ & $0.803 \pm 0.157$ \\
\hline Treatment $^{c}$ & 9.88 & 2,30 & 0.001 & 2.58 & 1,31 & 0.119 & $0.291 \pm 0.181$ & 18.9 & 1,31 & $<0.001$ & $0.658 \pm 0.151$ \\
\hline \multicolumn{12}{|l|}{ Number of neighbours } \\
\hline $\begin{array}{l}\text { Neolamprologus } \\
\text { pulcher }\end{array}$ & 8.41 & 2,30 & 0.001 & 12.5 & 1,31 & 0.001 & $0.102 \pm 0.029$ & 3.58 & 1,31 & 0.068 & $-0.046 \pm 0.024$ \\
\hline $\begin{array}{l}\text { Neolamprologus } \\
\text { savoryi }\end{array}$ & 3.71 & 2,30 & 0.036 & 0.27 & 1,31 & 0.605 & $-0.016 \pm 0.030$ & 7.08 & 1,31 & 0.012 & $0.067 \pm 0.025$ \\
\hline $\begin{array}{l}\text { Corrected model } \\
\text { adjusted } R^{2}\end{array}$ & & & & 0.317 & & & & 0.509 & & & \\
\hline
\end{tabular}

${ }^{a}$ Exact statistic based on Pillai's Trace

${ }^{\mathrm{b}}$ Hypothesis $d f$, error $d f$

${ }^{\mathrm{c}}$ Outside-colony shelters are set as the reference category and have a coefficient of zero

colony shelters were left more often unoccupied than within-colony shelters $\left(G_{1}=6.2, P=0.013\right.$, Table 3$)$. Second, occupied within-colony shelters were more often shared between two (groups of) cichlid species than occupied outside-colony shelters $\left(G_{1}=5.2, P=\right.$ 0.023 , Table 1). Although N. savoryi occurs at substantially lower densities than $N$. pulcher (Fig. 1), more dispersal shelters were occupied by $N$. savoryi (51\%) than by $N$. pulcher (14\%, Table 3$)$.

Biparental cichlids defended the dispersal shelters typically as a pair ( $n=4 T$. temporalis) or as a single breeding male ( $n=2 T$. temporalis, $2 N$. modestus, 1 $N$. tetracanthus) trying to attract females by digging and extending the shelter area. In contrast, cooperative breeders defended their newly acquired shelters with one to ten individuals (mean \pm SD: $3.7 \pm 2.9, n=$ $23)$; in this respect there were no differences between $N$. pulcher and $N$. savoryi $(U=25.5, P=0.14, n=5$, $n=18$, respectively), and between within- vs outsidecolony shelters $(U=25.5, P=0.68, n=20, n=3$, respectively). As expected, former helpers would occupy shelters preferentially as a group, i.e. more than just a single breeding pair ( $65 \%$ of cases, Fig. $5 a)$. This was corroborated by a significant difference in the number of final occupants per shelter comparing cooperatively breeding cichlids with the biparental cichlids $(U=29.5$, $n=23,9, P=0.001)$. Nevertheless, three dispersal shelters $(15 \%)$ each were only occupied by a single large $N$. savoryi disperser at the end of the observa- tion period, all at within-colony shelters. The original breeding group of $24 \mathrm{~N}$. pulcher and $13 \mathrm{~N}$. savoryi final occupants could be determined by their visiting behaviour and markings: 2, 3, 3, 6, 10 individual $N$. pulcher and 1, 1, 3, 4, 4 individual $N$. savoryi dispersed from the same original group into the same dispersal shelter. Hence, $100 \%$ N. pulcher and $85 \% N$. savoryi 'dispersed in groups'. We were uncertain about the group of origin of two N. pulcher and 46 $N$. savoryi occupants. If we conservatively assume that these final occupants all dispersed from different groups, at least $92 \% N$. pulcher and $22 \% N$. savoryi 'dispersed in groups'.

We also expected that large group members would disperse preferentially. The body sizes of the final occupants of the experimental shelters were compared to the body sizes of all group members of $N$. pulcher and $N$. savoryi, larger or equal to the smallest visitor seen of each species $(25 \mathrm{~mm} \mathrm{SL}$ in $N$. pulcher and $17.5 \mathrm{~mm} \mathrm{SL}$ in $N$. savoryi). As expected, final occupants were significantly larger than these samples of group members in both species (Fig. 5b, ANOVA on SL, effect of species: $F_{1,757}=29.7, P=0.04$, disperser or random group member: $F_{1,757}=11.0, P=$ 0.001, interaction: $F_{1,757}=0.09, P=0.77$; Levene's Test of equality of error variances was not significant: $\left.F_{3,753}=1.4, P=0.24\right)$.

Both dispersal shelter group size and disperser size were apparently influenced by the distance to the 
Table 3 Number of occupied experimental dispersal shelters per species within $(n=20)$ and outside $(n=15)$ the colonies of $N$. pulcher and $N$. savoryi at the end of the experiment

\begin{tabular}{|c|c|c|c|c|}
\hline \multirow[t]{2}{*}{ Species } & \multicolumn{2}{|c|}{$\begin{array}{l}\text { Number of } \\
\text { shelters }\end{array}$} & \multicolumn{2}{|c|}{$\begin{array}{l}\text { Size of breeders } \\
(\mathrm{SL} \mathrm{mm})\end{array}$} \\
\hline & $\begin{array}{l}\text { Within } \\
\text { colony }\end{array}$ & $\begin{array}{l}\text { Outside } \\
\text { colony }\end{array}$ & Males & Females \\
\hline Unoccupied & 2 & 7 & & \\
\hline Occupied & 18 & 8 & & \\
\hline \multicolumn{5}{|l|}{ Cooperative breeders } \\
\hline Neolamprologus pulcher & $4^{\mathrm{a}}$ & 1 & 60 & 52 \\
\hline Neolamprologus savoryi & $16^{\mathrm{abc}}$ & 2 & 59 & 44 \\
\hline \multicolumn{5}{|l|}{ Biparental breeders } \\
\hline Neolamprologus modestus & $1^{\mathrm{b}}$ & 1 & 83 & 80 \\
\hline $\begin{array}{l}\text { Neolamprologus } \\
\text { tetracanthus }\end{array}$ & 0 & 1 & 75 & 65 \\
\hline $\begin{array}{l}\text { Telmatochromis } \\
\text { temporalis }\end{array}$ & $3^{\mathrm{c}}$ & 3 & 55 & 45 \\
\hline
\end{tabular}

Also given are the mean estimated standard lengths SL of the male and female breeders for each species at the study site

$2 \times 2$ Table comparison unoccupied/occupied $\times$ within/outside colony: both species combined $G_{1}=5.6, P=0.018 ; N$. pulcher: $G_{1}=1.3, P=0.25 ; N$. savoryi: $G_{1}=16.7, P<0.001$

Six dispersal shelters were divided between two species:

${ }^{\text {a }}$ Shared between $N$. savoryi and $N$. pulcher: $n=3$

${ }^{\mathrm{b}}$ Shared between $N$. savoryi and $N$. modestus: $n=1$

${ }^{\mathrm{c}}$ Shared between $N$. savoryi and T. temporalis: $n=2$

nearest same species group (henceforth called 'ndistance'): first, the average dispersal shelter group size decreased with n-distance (regression on $\ln$ transformed (distance +0.001 ) $, F_{1,21}=5.3, P=0.032$, $n=23)$. Second, the size of the largest disperser in the group significantly decreased with n-distance (regression on ln-transformed (distance +0.001$), F_{1,21}=12.2$, $P=0.002, n=23$ ). Both relationships were affected by large breeder males from neighbouring groups incorporating the dispersal shelters into their own territory, if the dispersal shelter was close to their territory (4 out of 5 cases in $N$. pulcher and 2 out of 18 cases in $N$. savoryi). The n-distance was significantly smaller when this occurred (median $=0.1 \mathrm{~m}, n=6)$ then when this did not occur (median=0.9 $\mathrm{m}, n=17, U=14, P=$ 0.009). Additionally, a relatively large number of helpers moved over to this new patch when such a breeder male extended his territory to the vacant site. The breeder males formed a polygynous pairbond with the largest female helper in the disperser group, while keeping their original breeder female in the home territory. In contrast, breeder males seemed incapable of monopolizing a dispersal shelter when it was further away from their home territory. Instead, these shelters were occupied by large helper males and females who started to breed independently. Ten of these new pairs recruited additional helpers to their shelter to assist them, whereas seven did not. The number of these additional helpers tended to decline with n-distance, but this relationship was not significant (regression on ln-transformed (distance +0.001 ), $\left.F_{1,16}=2.9, P=0.11, n=17\right)$.

\section{Mechanisms of dispersal shelter occupation}

Three potential mechanisms could explain why certain shelters were occupied. These were assessed simultaneously by forward selection logistic regressions on whether the dispersal shelters were colonised by $N$. pulcher or $N$. savoryi by entering three keyvariables simultaneously. First, an effect of 'colony' (categorical variable: inside- or outside the colony) would support a preference or avoidance of outside against inside colony shelters. Second, an effect of the number of neighbours within $3 \mathrm{~m}$ distance from the dispersal shelter would support a preference to occupy nearby shelters (covariate: number of $N$. pulcher or number of $N$. savoryi groups). Third, a negative effect of the visitation rate by a particular fish species (e.g. predators or shelter competitors) would support avoidance of shelters used by heterospecifics (19 covariates: visitation rates by each species). A logistic regression on whether the dispersal shelter was occupied by $N$. pulcher (coded 0 when 'no' and 1 when 'yes') revealed a marginally non-significant effect of 'colony' $\left(G_{1}=3.9, P=0.066\right)$, whereas the number of neighbouring $N$. pulcher groups within $3 \mathrm{~m}\left(G_{1}=0.4, P=0.53\right)$ and the visitation rates by any of the other fish species (all $G_{1}<2.4, P>0.12$, excluding $N$. pulcher) did not significantly affect this likelihood. A similar logistic regression on whether the dispersal shelter was occupied by $N$. savoryi revealed a significant effect of 'colony' $\left(G_{1}=16.7, P<0.0001\right)$, whereas the number of neighbouring $N$. savoryi groups within $3 \mathrm{~m}\left(G_{1}=0.004, P=0.95\right)$ and the visitation rates by any of the other fish species (all $G_{1}<1.4, P>0.24$, excluding $N$. savoryi) did not significantly affect this likelihood. Overall, the results suggest that whether 


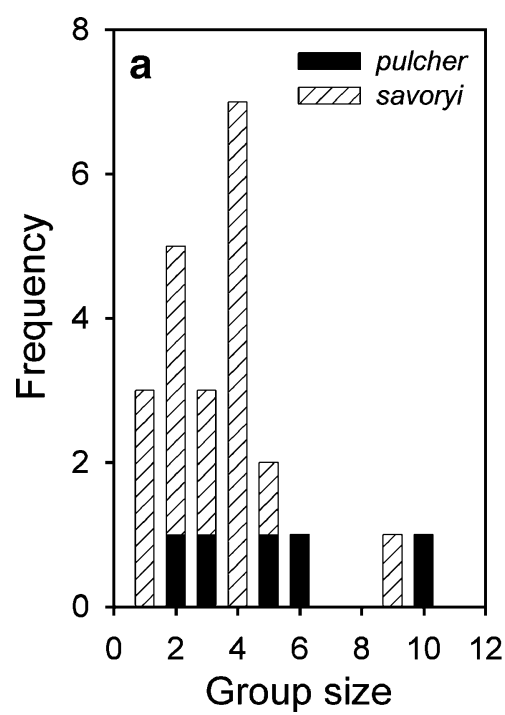

Fig. 5 a Number of final occupants ('dispersers') per experimental dispersal shelter. b Average body sizes of dispersers (black dots) compared to a random sample of group members equal or

the dispersal shelter was located inside the colony was the only factor increasing final occupancy rate.

The visitation rates of $N$. pulcher or $N$. savoryi very well predicted whether a dispersal shelter was finally occupied by these species (two additional logistic regressions, effect of the visitation rate by $N$. pulcher or $N$. savoryi on whether the shelter was finally occupied by $N$. pulcher or $N$. savoryi: $G_{1}=$ 10.2 and 48.5, $P=0.001$ and $<0.0001$, respectively).

\section{Discussion}

Habitat selection and coloniality

Cooperatively breeding cichlids often breed in colonies (e.g. Kuwamura 1997), and in some cases is apparently related to the patchy distribution of the respective breeding habitat (e.g. the availability of empty snailshells as breeding substrate for Neolamprologus multifasciatus, Kohler 1998). Our results suggest that variation and patchiness in habitat quality cannot explain the existence of colonies in the populations of $N$. pulcher and N. savoryi studied at Kasakalawe due to three reasons.

First, despite both study species showing a slight preference for more stony areas, $40 \%$ of the preferred habitat remained unoccupied. The average percentage stone cover inside the colonies was only slightly higher

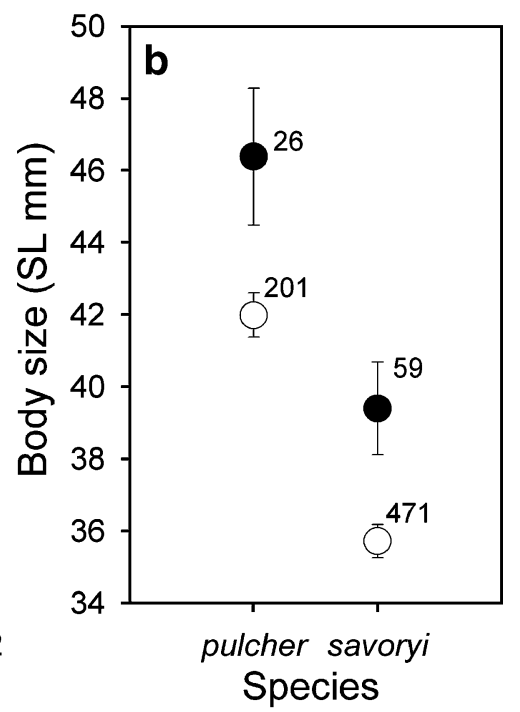

larger in size to the smallest group member seen to visit the experimental shelters (white dots). Depicted are means $\pm \mathrm{SE}$ with sample sizes

than in the directly adjacent area, despite the fact that digging activity of the breeding groups increases the proportion of stone cover by unearthing stones from the sand surface. Second, densities and sizes of predators, shelter competitors and other species potentially competing for food, were comparable between the withincolony and adjacent outside-colony areas, suggesting that cooperatively breeding cichlids did not avoid areas with higher predation risk or higher densities of competitors for shelters and food. In fact, densities tended to be higher within the colony for most species, which might be due e.g. to predators being attracted by the large number of potential prey (eggs, offspring and adults) living in these colonies ( $N$. pulcher and $N$. savoryi being the predominant species within them). Third, potential differences in food availability are unlikely to cause particular habitat preferences since they are mainly zooplanktivores (Kondo 1986; Gashagaza 1988). Hence, the major food resource can neither be predicted on the basis of percentage stone cover, nor be monopolised.

Dispersal to inside and outside colony shelters

Alternatively, breeding in colonies might be due to the benefits of living in aggregations. We found that group size decreases the individual predation risk in $N$. pulcher (Heg et al. 2004), and we argued that living in colonies may also reduce the individual 
predation risk. The results of our dispersal experiments reported here were consistent with this hypothesis, suggesting that Allee effects are important for cooperative cichlid dispersal behaviour (Allee 1951). Within-colony independent breeding sites were preferred by dispersing helper cichlids, compared to outside colony sites. This result was significant for both species combined and for $N$. savoryi alone, but not for $N$. pulcher alone. However, since both cooperative species competed for the vacant shelters, results for the single species are more difficult to interpret. This effect was already apparent in the cichlid's visitation behaviour of the dispersal shelters, a high visitation rate being a good predictor of final occupation of a shelter.

We propose three mutually non-exclusive mechanisms accounting for a preference of within-colony shelters: (1) direct preference for shelters within the colony; (2) preferred visitation of nearby groups (consistent with cichlids showing limited ranging and dispersal behaviour under the risk of predation; see Heg et al. 2004); (3) avoidance of shelters visited by other species, e.g. predator or shelter competitors. Shelters with a higher number of neighbouring groups were more often visited, supporting mechanism (2) (see also Bergmüller et al. 2005a; Heg et al. 2005b). But even when controlling for this effect, withincolony shelters were more often visited than outsidecolony shelters: whether a dispersal shelter was eventually colonised was mainly determined by whether it was located inside or outside the colony, which supports mechanism (1). The visitation rates and whether a shelter was eventually colonised were not affected by the visitation rates of any other fish species, including predators and shelter competitors, so mechanism (3) was not supported. We conclude that both (1) and (2) seem to operate as mechanisms for dispersal behaviour, where (1) may relate to the long-term benefits of obtaining a within-colony shelter for independent breeding, reducing e.g. the long-term risk of predation, and where (2) may relate to the immediate costs of dispersal or visiting behaviour due to e.g. predation risk during prospecting behaviour (see also Bergmüller et al. 2005a, b). Both mechanisms of predation risk reduction may operate to promote and maintain colonial breeding in these cichlids. In addition, the cichlids preferred to disperse in groups, including males extending their territory and breeding polygynously with new female breeders (see also Stiver et al. 2006), and longdistance dispersal by groups of helpers.

Competition for the dispersal shelters

Competition for the dispersal shelters was most severe between the cooperatively breeding cichlids as indicated by their high visitation rates of these shelters compared to the outside colony shelters. $N$. savoryi finally occupied more experimental dispersal shelters than $N$. pulcher, despite both having similar visitation rates. We expected severe competition to occur between both species for the shelters, but did not have a clear prediction which species might win the competition, since both are very similar in size. This difference in occupation rate between the two species might relate to social differences or microecological preferences needing further investigation. The outcome of our experiment could have been influenced also by competition with other biparental, Lamprologine cichlids. The results suggested that the only significant biparental competitor is T. temporalis. At our study site, adults and particular females of this species are on average smaller than the adults of both cooperatively breeding cichlids. Behavioural observations suggests that $N$. savoryi and $N$. pulcher are usually able to evict this smaller species from their shelters (D. Heg, personal observations).Visitation rates of other fish species to both types of shelters was generally very low, except for the species which were not competitors for breeding shelters, but used the stone surface for feeding. Overall, none of the visitation rates of other fish species predicted whether a shelter would be visited or occupied by $N$. pulcher or $N$. savoryi, suggesting that competition of other cichlids for the experimental shelters were not affecting our results.

Territory extension of male breeders was more likely to occur when dispersal shelters were close to their home territory, which may be the major route for female helpers to acquire a breeding position (see also Limberger 1983). Small helpers in particular appear to be reluctant to cross a large stretch of sand to check out new breeding sites (see also Stiver et al. 2004; Bergmüller et al. 2005a). As outlined above, the vacant shelters attracted more occupants when close to occupied neighbouring groups, suggesting that the likelihood of dispersal depends on a combination of the dispersal distance and helper size. Isolation-by- 
distance between colonies of $N$. pulcher also suggests cichlids are reluctant to disperse over longer distances (Stiver et al. 2004).

\section{Benefits and costs of sociality}

This is the first study suggesting that Allee effects are important for dispersal behaviour of cooperatively breeding fish, a phenomenon which has been described in settlement studies of pelagic larval fish (e.g. Sweatman 1983, 1985; Booth 1992; Booth and Wellington 1998) and also occurs in various other animal taxa (e.g. Stamps 1988, 2001; Danchin et al. 2001). Theoretical models predict that Allee effects may play a major role in habitat selection (e.g. Greene and Stamps 2001) and animal population dynamics (e.g. Courchamp et al. 1999a), generating patterns of colonisation and extinction which might be particularly important in species living in small, more or less isolated populations (Stephens and Sutherland 1999). In this respect, cooperative breeders like the cichlids studied here provide an interesting model case, because of their unique 'hierarchical' spatial and social organisation, i.e. individuals may form alliances and stay in groups, groups cluster in colonies, colonies might form super-colonies and finally populations. At each level of social organisation 'Allee effects' might occur, i.e. at the level of 'alliances' e.g. Heinsohn et al. 2000); 'groups' (e.g. Field et al. 1999; Balshine et al. 2001; Tibbetts and Reeve 2003; Heg et al. 2005b); 'colony' (this study); or 'local population density' effects (Courchamp et al. 1999b).

Predation risk is a major candidate for generating Allee effects at several levels simultaneously (Courchamp et al. 2000). Many cooperatively breeding species show cooperative predator defence (e.g. Taborsky 1984; Rasa 1987; Stacey and Koenig 1990; Kudo et al. 1995; Balshine-Earn et al. 1998; Arnold 2000). In some species, including our study species, this creates opportunities to deter predators which are substantially larger than they are themselves. In separate experimental studies on $N$. pulcher we have shown that group size affects reproductive success (Taborsky 1984; Brouwer et al. 2005) and that group size decreases the negative impact of predators on helper survival and dispersal (Heg et al. 2004). However, without predation risk helpers quickly disperse and can successfully produce a clutch within 4 days after dispersal (Bergmüller et al. 2005b).
Future studies should measure the fitness consequences of grouping, and the opposite: the costs of aggregating and clumping, at each 'level of aggregation'. We believe that studying the benefits and costs of group size to each individual in cooperative breeders will be necessary to understand the ultimate evolutionary causes of cooperative breeding. It may clarify also why in some species or in some groups, groups show a stable group composition or may even attract immigrants, whereas in others groups experience high emigration rates or split-up into smaller groups. An increase in group size might initially increase the breeders' reproductive success and the survival of all members (see also Heg et al. 2005b). However, above some density-dependent threshold this may not outweigh a decrease in individual fitness, at least for some group members, due to increased within-group competition for reproduction (Skubic et al. 2004; Heg et al. 2006) and other vital resources (Werner et al. 2003), at which point group splitting, budding and subordinate dispersal may be favoured.

Acknowledgments We thank C. Kapasa, H. Phiri, R. Shapola, L. Makasa, D. Sinyinza and C. Lukwesa from the Department of Fisheries, Zambia Ministry of Agriculture and Co-operatives for their continuous support of our project. We thank the members of the Lake Tanganyika Diving Expeditions 2002 and 2003 for their assistance. We are grateful to Rolf Eggler, Susanne Maurer and Peter Stettler for logistical support and Ralph Bergmüller and anonymous reviewers for comments on the manuscript. The project was supported by the Swiss National Science Foundation (SNF grant 3100-064396 to M.T.). D.H. is supported by SNF grant 3100A0-108473. The experiments conducted in this study comply with the current laws of the country, Zambia, in which they were performed.

\section{References}

Allee WC (1951) The social life of animals. Beacon Press, Boston

Arnold KE (2000) Group mobbing behaviour and nest defence in a cooperatively breeding Australian bird. Ethology 106:385-393

Balshine S, Leach B, Neat F, Reid H, Taborsky M, Werner N (2001) Correlates of group size in a cooperatively breeding cichlid fish (Neolamprologus pulcher). Behav Ecol Sociobiol 50:134-140

Balshine-Earn S, Neat FC, Reid H, Taborsky M (1998) Paying to stay or paying to breed? Field evidence for direct benefits of helping behavior in a cooperatively breeding fish. Behav Ecol 9:432-438

Bergmüller R, Heg D, Peer K, Taborsky M (2005a) Extended safe havens and between-group dispersal of helpers in a cooperatively breeding cichlid. Behaviour 142:1643-1667 
Bergmüller R, Heg D, Taborsky M (2005b) Helpers in a cooperatively breeding cichlid stay and pay or disperse and breed, depending on ecological constraints. Proc Royal Soc Lond B 272:325-331

Booth DJ (1992) Larval settlement patterns and preferences by domino damselfish Dascyllus albisella Gill. J Exp Mar Biol Ecol 155:85-104

Booth DJ, Wellington G (1998) Settlement preferences in coralreef fishes: effects on patterns of adult and juvenile distributions, individual fitness and population structure. Austr J Ecol 23:274-279

Brichard P (1997) Atlas der Tanganjikasee cichliden, Band 1. Bede-Verlag, Ruhmannsfelden

Brichard P (1999) Atlas der Tanganjikasee cichliden, Band 2. Bede-Verlag, Ruhmannsfelden

Brouwer L, Heg D, Taborsky M (2005) Experimental evidence for helper effects in a cooperatively breeding cichlid. Behav Ecol 16:667-673

Buston P (2003) Forcible eviction and prevention of recruitment in the clown anemonefish. Behav Ecol 14:576-582

Choe JC, Crespi BJ (1997) The evolution of social behavior in insects and arachnids. Cambridge University Press, Cambridge

Courchamp F, Clutton-Brock T, Grenfell B (1999a) Inverse density dependence and the Allee effect. Trends Ecol Evol 14:405-410

Courchamp F, Grenfell B, Clutton-Brock T (1999b) Population dynamics of obligate cooperators. Proc Royal Soc Lond B 266:557-563

Courchamp F, Grenfell BT, Clutton-Brock TH (2000) Impact of natural enemies on obligately cooperative breeders. Oikos 91:311-322

Crawley MJ (2002) Statistical computing. An introduction to data analysis using S-plus. Wiley, Chichester

Danchin E, Heg D, Doligez B (2001) Public information and breeding habitat selection. In: Clobert J, Danchin E, Dhondt AA, Nichols JD (eds) Dispersal: individual, population, and community. Oxford University Press, Oxford, pp 243-258

Dierkes P, Heg D, Taborsky M, Skubic E, Achmann R (2005) Genetic relatedness in groups is sex-specific and declines with age of helpers in a cooperatively breeding cichlid. Ecol Lett 8:968-975

Duplessis MA (1992) Obligate cavity roosting as a constraint on dispersal of green (red-billed) woodhoopoes - consequences for philopatry and the likelihood of inbreeding. Oecologia 90:205-211

Emlen ST (1995) An evolutionary theory of the family. Proc Natl Acad Sci U S A 92:8092-8099

Field J, Shreeves G, Sumner S (1999) Group size, queuing and helping decisions in facultatively eusocial hover wasps. Behav Ecol Sociobiol 45:378-385

Gashagaza MM (1988) Feeding activity of a Tanganyikan cichlid fish Lamprologus brichardi. Afr Study Monogr 9:1-9

Goldizen AW, Putland DA, Robertson KA (2002) Dispersal strategies in Tasmanian native hens (Gallinula mortierii). Behav Ecol 13:328-336

Greene CM, Stamps JA (2001) Habitat selection at low population densities. Ecology 82:2091-2100
Hatchwell BJ, Komdeur J (2000) Ecological constraints, life history traits and the evolution of cooperative breeding. Anim Behav 59:1079-1086

Heg D, Bachar Z (2006) Cooperative breeding in the Lake Tanganyika cichlid Julidochromis ornatus. Environ Biol Fish 76:265-281

Heg D, Bachar Z, Brouwer L, Taborsky M (2004) Predation risk is an ecological constraint for helper dispersal in a cooperatively breeding cichlid. Proc Royal Soc Lond B271:2367-2374

Heg D, Bachar Z, Taborsky M (2005a) Cooperative breeding and group structure in the Lake Tanganyika cichlid Neolamprologus savoryi. Ethology 111:1017-1043

Heg D, Brouwer L, Bachar Z, Taborsky M (2005b) Large group size yields group stability in the cooperatively breeding cichlid Neolamprologus pulcher. Behaviour 142:1615-1641

Heg D, Bergmüller R, Bonfils D, Otti O, Bachar Z, Burri R, Heckel G, Taborsky M (2006) Cichlids do not adjust reproductive skew to the availability of independent breeding options. Behav Ecol 17:419-429

Heinsohn R, Dunn P, Legge S, Double M (2000) Coalitions of relatives and reproductive skew in cooperatively breeding white-winged choughs. Proc Royal Soc Lond B 267:243-249

Koenig WD, Dickinson JL (2004) Ecology and evolution of cooperative breeding in birds. Cambridge University Press, Cambridge

Koenig WD, Pitelka FA, Carmen WJ, Mumme RL, Stanback MT (1992) The evolution of delayed dispersal in cooperative breeders. Quart Rev Biol 67:111-150

Kohler U (1998) Zur Struktur und Evolution des Sozialsystems von Neolamprologus multifasciatus (Cichlidae, Pisces), dem kleinsten Schneckenbuntbarsch des Tanganjikasees. Shaker Verlag, Aachen

Komdeur J (1992) Importance of habitat saturation and territory quality for evolution of cooperative breeding in the seychelles warbler. Nature 358:493-495

Komdeur J (1994) Experimental evidence for helping and hindering by previous offspring in the cooperative-breeding seychelles warbler Acrocephalus sechellensis. Behav Ecol Sociobiol 34:175-186

Komdeur J, Edelaar P (2001) Male seychelles warblers use territory budding to maximize lifetime fitness in a saturated environment. Behav Ecol 12:706-715

Konings A (1998) Tanganyika cichlids in their natural habitat. Cichlid, El Paso

Kondo T (1986) Feeding habits of Lamprologus savoryi (Teleostei: Cichlidae) with reference to its social behaviour. Physiol Ecol 23:1-15

Kudo SI, Ishibashi E, Makino S (1995) Reproductive and subsocial behaviour in the ovoviviparous leaf beetle Gonioctena sibirica (Coleoptera: Chrysomelidae). Ecol Entomol 20:367-373

Kurki H, Vuorinen I, Bosma E, Bwebwa D (1999) Spatial and temporal changes in copepod zooplankton communities of Lake Tanganyika. Hydrobiol 407:105-114

Kuwamura T (1997) The evolution of parental care and mating systems among Tanganyikan cichlids. In: Kawanabe $\mathrm{H}$, Hori M, Nagoshi M (eds) Fish communities in Lake Tanganyika. Kyoto University Press, Kyoto, pp 59-86 
Ligon JD, Ligon SH, Ford HA (1991) An experimental study of the bases of male philopatry in the cooperatively breeding superb fairy-wren Malurus cyaneus. Ethology 87:134-148

Limberger D (1983) Pairs and harems in a cichlid fish, Lamprologus brichardi. Z Tierpsychol 62:115-144

Macedo RH, Bianchi CA (1997) Communal breeding in tropical guira cuckoos Guira guira: sociality in the absence of a saturated habitat. J Avian Biol 28:207-215

Pruett-Jones SG, Lewis MJ (1990) Sex ratio and habitat limitation promote delayed dispersal in superb fairywrens. Nature 348:541-542

Rasa OAE (1987) The dwarf mongoose: a study of behavior and social structure in relation to ecology in a small, social carnivore. Adv Study Behav 17:121-163

Skubic E, Taborsky M, McNamara JM, Houston AI (2004) When to parasitize? A dynamic optimization model of reproductive strategies in a cooperative breeder. J Theor Biol 227:487-501

Stacey PB, Koenig WD (1990) Cooperative breeding in birds. Cambridge University Press, Cambridge

Stacey PB, Ligon JD (1987) Territory quality and dispersal options in the acorn woodpecker, and a challenge to the habitat-saturation model of cooperative breeding. Am Nat 130:654-676

Stacey PB, Ligon JD (1991) The benefits-of-philopatry hypothesis for the evolution of cooperative breeding - variation in territory quality and group size effects. Am Nat 137:831-846

Stamps JA (1988) Conspecific attraction and aggregation in territorial species. Am Nat 131:329-347

Stamps JA (2001) Habitat selection by dispersers: integrating proximate and ultimate approaches. In: Clobert J, Danchin E, Dhondt AA, Nichols JD (eds) Dispersal: individual, population, and community. Oxford University Press, Oxford, pp 230-242
Stephens PA, Sutherland WJ (1999) Consequences of the Allee effect for behaviour, ecology and conservation. Trends Ecol Evol 14:401-405

Stiver KA, Dierkes P, Taborsky M, Balshine S (2004) Dispersal patterns and status change in a co-operatively breeding cichlid: evidence from microsatellite analyses and behavioural observations. J Fish Biol 65:91-105

Stiver KA, Fitzpatrick J, Desjardins JK, Balshine S (2006) Sex differences in rates of territory joining and inheritance in a cooperatively breeding cichlid fish. Anim Behav 71:449-456

Sweatman HPA (1983) Influence of conspecifics on choice of settlement sites by larvae of two pomacentrid fishes (Dascyllus aruanus and D. reticulatus) on coral reefs. Mar Biol 75:222-229

Sweatman HPA (1985) The influence of adults of some coral reef fishes on larval recruitment. Ecol Monogr 55:469-485

Taborsky M (1984) Broodcare helpers in the cichlid fish Lamprologus brichardi: their costs and benefits. Anim Behav 32:1236-1252

Taborsky M (1994) Sneakers, satellites, and helpers: parasitic and cooperative behavior in fish reproduction. Adv Study Behav 23:1-100

Taborsky M, Limberger D (1981) Helpers in fish. Behav Ecol Sociobiol 8:143-145

Tibbetts EA, Reeve HK (2003) Benefits of foundress associations in the paper wasp Polistes dominulus: increased productivity and survival, but no assurance of fitness returns. Behav Ecol 14:510-514

Werner NY, Balshine S, Leach B, Lotem A (2003) Helping opportunities and space segregation in cooperatively breeding cichlids. Behav Ecol 14:749-756

Zar JH (1984) Biostatistical analysis. Prentice Hall, Englewood Cliffs 